See discussions, stats, and author profiles for this publication at: https://www.researchgate.net/publication/345148233

\title{
Radiografía de la pandemia: análisis de la cobertura periodística de la Covid19 en portadas de periódicos
}

Article in El Profesional de la Informacion · November 2020

DOI: 10.3145/epi.2020.sep.23

\section{CITATIONS}

0

3 authors:

Juan Ignacio Cantero de Julián University of Castilla-La Mancha 21 PUBLICATIONS 81 CITATIONS

SEE PROFILE

José María Herranz de la Casa

University of Castilla-La Mancha

87 PUBliCATIONS 347 CITATIONS

SEE PROFILE

Some of the authors of this publication are also working on these related projects:

Governance, transparency and accountability - Journalism View project

Project TikTok and the changing paradigm of digital communication View project
READS

944

Pavel Sidorenko Bautista

Universidad Francisco de Vitoria

36 PUBLICATIONS 90 CITATIONS

SEE PROFILE 


\title{
Radiografía de la pandemia: análisis de la cobertura periodística de la Covid-19 en portadas de periódicos
}

\author{
Radiography of the pandemic: analysis of the \\ journalistic coverage of the Covid-19 on the front \\ pages of newspapers
}

\author{
Juan-Ignacio Cantero-de-Julián; Pavel Sidorenko-Bautista; José-María \\ Herranz-de-la-Casa
}

Cómo citar este artículo:

Cantero-de-Julián, Juan-Ignacio; Sidorenko-Bautista, Pavel; Herranz-de-la-Casa, José-María (2020). "Radiografía de la pandemia: Análisis de la cobertura periodística de la Covid-19 en portadas de periódicos". Profesional de la información, v. 29, n. 5, e290523.

https://doi.org/10.3145/epi.2020.sep.23

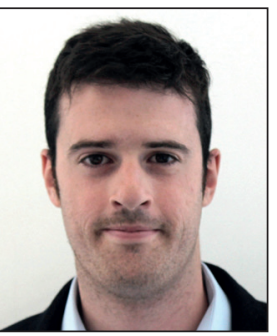

Juan-Ignacio Cantero-de-Julián https://orcid.org/0000-0002-6631-1915

Universidad de Castilla-La Mancha

Facultad de Comunicación

Campus Universitario, $\mathrm{s} / \mathrm{n}$.

16071 Cuenca, España

juanignacio.cantero@alu.uclm.es $\bigotimes$

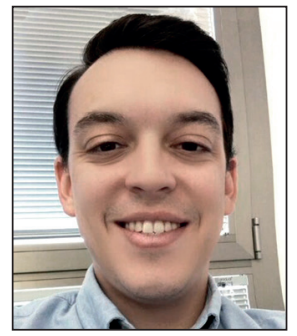

Pavel Sidorenko-Bautista

https://orcid.org/0000-0002-8094-3089

Universidad Francisco de Vitoria

Facultad de Ciencias de la Comunicación

Crta. Pozuelo Majadahonda, Km 1.800

28223 Pozuelo de Alarcón (Madrid),

España

pavel.sidorenko@ufv.es

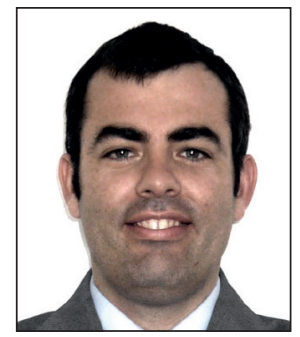

\author{
José-María Herranz-de-la-Casa \\ https://orcid.org/0000-0002-3667-2664 \\ Universidad de Castilla-La Mancha \\ Facultad de Comunicación \\ Campus Universitario, $\mathrm{s} / \mathrm{n}$. \\ 16071 Cuenca, España \\ josemaria.herranz@uclm.es
}

\section{Resumen}

La Covid-19 ha provocado una situación completamente extraordinaria y anómala. El nuevo coronavirus se ha convertido en un fenómeno global tras la declaración de un estado pandémico que afecta a todos los campos: sanitario, económico, social, científico, medioambiental, etc. Esta emergencia sanitaria afecta también a distintos niveles y actores, entre ellos los medios y el periodismo. En lo que a cobertura informativa se refiere, la portada de prensa representa un objeto de estudio relevante desde el punto de vista periodístico, pero también sociológico e historiográfico. La página principal juega un importante papel temporal explicativo, especialmente durante un evento tan disruptivo como la pandemia. Ofrece la posibilidad de "fotografiar" la cobertura de un acontecimiento en curso. El objetivo de esta investigación es analizar la cobertura del nuevo coronavirus y su evolución a lo largo del primer trimestre de 2020. Para responder a estas cuestiones, se realiza un análisis de contenido temático de 630 portadas de siete periódicos generalistas españoles de alcance nacional: El país, El mundo, ABC, La razón, La vanguardia, El periódico y El correo. Los resultados indican que la información sobre el virus ha ido aumentando progresivamente según la epidemia se hacía más próxima hasta estar dentro de las fronteras españolas. También que la cobertura fue muy homogénea en los diarios españoles, aunque se localizan algunas diferencias sobre todo por tendencias editoriales y por perspectiva regional o nacional. Asimismo, el patrón de los encuadres analizados se caracteriza por el diagnóstico actual de la pandemia muy enfocado en la definición del problema y la propuesta de soluciones sanitarias. 


\title{
Palabras clave
}

Covid-19; Coronavirus; Pandemias; Diarios; Periódicos; Consumo de noticias; Portadas; Medios tradicionales; Cobertura periodística; Agenda mediática; Encuadres; Encuadres interpretativos; Información periodística; Periodismo.

\begin{abstract}
Covid-19 has resulted in a totally extraordinary and anomalous situation. This new coronavirus became a global phenomenon after the declaration of a pandemic state, which affects all fields: health, economic, social, scientific, environmental, etc. This health emergency affects many different levels and actors, including media and journalism. As far as news coverage is concerned, the front page of the press represents a relevant object of study from a journalistic, as well as sociological and historiographical, point of view. The front page plays an important temporary explanatory role, especially during an event as disruptive as the pandemic. It offers the possibility to take a "snapshot" of the coverage of an ongoing event. The aim of this research is to analyze the coverage of the new coronavirus and its evolution throughout the first quarter of 2020. To answer these questions, a thematic content analysis of 630 front pages of seven Spanish national generalist newspapers (El país, El mundo, ABC, La razón, La vanguardia, El periódico, and El correo) was carried out. The results indicated that information about the virus increased progressively as the epidemic approached the Spanish borders. The coverage in the Spanish newspapers was highly homogeneous, although some differences can be found, mainly due to editorial trends and regional or national perspectives. The pattern of the analyzed samples is characterized by the current diagnosis of the pandemic, highly focused on the definition of the problem and the proposal of health solutions.
\end{abstract}

\section{Keywords}

Covid-19; Coronavirus; Pandemics; Newspapers; News consumption; Front pages; Traditional media; Journalistic coverage; Media agenda; Framing; Interpretative frameworks; Journalistic information; Journalism.

\section{Introducción}

Desde principios de enero de 2020, la atención de la comunidad médico-científica se ha centrado en la epidemia causada por el nuevo coronavirus SARS-CoV-2. El virus surgió en Wuhan (China) a finales de 2019 y sigue extendiéndose a pesar de los esfuerzos sin precedentes realizados en todo el mundo para contenerlo. El 31 de diciembre de 2019 se notificó el primer caso del brote en China y el 7 de enero, las autoridades chinas lo identificaron como un nuevo coronavirus. El 11 de febrero la Organización Mundial de la Salud (OMS) nombró a la enfermedad como Covid-19 y el 11 de marzo la declaró pandemia.

Ante una crisis sanitaria, la comunicación de los riesgos a los ciudadanos es crucial para difundir mensajes que ayuden a la población a conocer los orígenes, las amenazas, el nivel de alerta y las medidas a adoptar. Los medios de comunicación juegan junto a los profesionales sanitarios un papel decisivo en la gestión y el conocimiento de crisis sanitarias con respecto a la información, las percepciones y la toma de decisiones (Lubens, 2015). Se han constituido como la principal fuente de información en materia de percepción de riesgos (Major; Atwood, 2004), recogiendo las amenazas invisibles del entorno y haciéndolas visibles (Farré-Coma, 2005).

Sin un conjunto compacto de temas o asuntos por resolver, ordenados por prioridades, la función de la sociedad sería imposible (Shaw; Martin, 1992). El problema es, tal y como señalan Herranz-de-la-Casa y Cantero-de-Julián (2019), que muchas veces la necesidad de simplificar la realidad puede generar sesgos y errores de percepción.

Las coberturas de los distintos medios son semejantes, ya que no sólo publican los mismos temas sino que ofrecen un tratamiento similar. Este fenómeno se denomina "homogeneidad, consonancia o conformidad" (Donohue; Glasser, 1978; Riffe; Shaw, 1982).

Muchas de las variaciones del impacto de los medios en la percepción de riesgo se deben a los diferentes estilos de presentar las noticias (Peterson; Thompson 2009). Los medios de comunicación organizan y tratan la información mediante diversas orientaciones o puntos de vista sobre un mismo tema (McCombs; Shaw, 1972; Scheufele, 2004; Igartua-Perosanz; Humanes, 2004; Muñiz, 2015). Cuando el periodista plantea una noticia, selecciona un determinado encuadre para su construcción (McCombs, 2005), sin embargo, podría haber elegido otro, enfatizando distintos aspectos, seleccionando otras fuentes o titulando de manera diferente (Van-Gorp, 2007).

Una de las líneas más relevantes y con mayor aplicación en el análisis del tratamiento en los medios de comunicación es el concepto de encuadre, que establece la presentación por parte de los periodistas de los acontecimientos poniendo énfasis o prescindiendo de posibles aspectos de la realidad (Gitlin, 1980; Entman, 1993; Reese, 2001; D’Angelo, 2002; De-Vreese, 2005; Scheufele, 2004; Bryant; Miron, 2004; Weaver, 2007; Lecheler; De-Vreese, 2012; Matthes, 2012; Koziner, 2013; Muñiz, 2015).

En cuanto a la influencia del encuadre en epidemias sanitarias como la gripe A, investigaciones anteriores (Faridah; Normah; Chang, 2010; Idoyaga et al., 2012) revelaron que los marcos más utilizados fueron el de la atribución de responsabilidad y el de interés humano. Los encuadres resultan de especial interés en el análisis de estos ejes temáticos. El estudio de Hallin et al. (2020) acerca de las noticias sobre la gripe A (H1N1) de 2009 en Argentina, Estados Unidos y Venezuela, indica también que los periódicos consiguieron movilizar la atención pública y contener la alarma sobre el virus. 


\section{Papel de la prensa tradicional frente a la pandemia de la Covid-19}

Los datos del estudio del Digilab (Masip et al., 2020) referidos al período del 3 al 10 de abril, muestran que la crisis del coronavirus ha provocado que el $78 \%$ de los ciudadanos se informe más que antes. El $52 \%$ lo hace tres o más veces al día, cuando antes de la crisis sólo lo hacía el $28 \%$, y un $90 \%$ de los españoles se informa al menos una vez al día sobre la Covid-19. La mayoría $(77,4 \%)$ cree que los medios sesgan la información conforme a su línea editorial, y un 44,6\% se queja de sensacionalismo y cree que han generado una alarma innecesaria.

La investigación de Casero-Ripollés (2020) demuestra que en situaciones críticas de riesgo para la vida humana los ciudadanos demandan información y noticias. Ante un contexto informativo complejo, opta por fuentes informativas identificadas y con amplia trayectoria. Asimismo, los datos muestran que los medios tradicionales obtienen porcentajes más altos en el consumo de noticias y su cobertura informativa es percibida más positivamente, vinculada a la credibilidad y confianza. La prensa y la televisión han sido identificados como los dos medios de referencia en otras crisis sanitarias (Park; Boatwright; Avery, 2019). En situaciones de crisis, las audiencias suelen concentrarse con más incidencia en los medios tradicionales: prensa, radio y televisión (Hornmoen; Backholm, 2018).

El estudio de Havas Media Group España (2020) indica que el conocimiento del coronavirus en los españoles alcanza el $100 \%$ y que el $80 \%$ afirma que la alarma social a causa del coronavirus es ya alta o muy alta. El mayor impacto se observa en los cambios de hábitos derivados del aislamiento, entre los que el 15\% destaca la necesidad de información fiable. Esta encuesta señala que los ciudadanos confían en mayor medida en los medios tradicionales. En una escala de 1 a 7 , la prensa recibe 5,1, muy por encima de internet $(4,1)$ y redes sociales $(3,5)$. Rodero $(2020)$ muestra que durante el confinamiento propiciado por la pandemia de la Covid-19, el consumo de información a través de redes sociales ha sido minoritario.

El Eurobarómetro 2017 (European Commission, 2017) reafirma estos índices de credibilidad y señala que, pese a que la prensa no se encuentra entre los medios con más audiencia, sí que está entre los que más confianza generan. Según estos datos, en España se considera a la prensa el segundo medio más creíble, sólo por detrás de la radio y muy por encima de internet.

El informe del Reuters Institute (Nielsen et al., 2020) señala que los medios de comunicación en España han ayudado a comprender la crisis (56\% de los encuestados) y explicar las medidas de contención a los ciudadanos (64\%). Sin embargo, aproximadamente uno de cada tres (32\%) siente que los medios de comunicación han exagerado la pandemia.

La portada impresa supone una fuente interesante ya que condensa y comprime los primeros significados, interpretaciones y narraciones de lo que está sucediendo y adquieren una posición representativa como espacio que realiza una captura de un tiempo muy específico (Niemeyer, 2019), especialmente cuando se produce durante un evento disruptivo en los medios como es la Covid-19. Ocupa un lugar intermedio entre las coberturas "en vivo" y el análisis que intenta narrar al detalle los hechos y consecuencias en los siguientes días. Es una forma periodística muy especial que permite contemplar las temporalidades de las noticias en otro nivel.

Estudios recientes en España (Canales; Lizárraga, 2019; Rojas-Torrijos; Jimeno-López, 2019; Pérez-Curiel; Jiménez-Marín; García-Medina, 2020) han centrado su atención en las portadas y el encuadre para comprobar la influencia de los medios en la selección de la agenda y los enfoques temáticos. También en las portadas de las revistas de muy diferentes temáticas como el sentimiento de identidad (Cantrell-Rosas-Moreno; Harp; Bachmann, 2013) o el medio ambiente (Meisner; Takahasi, 2013).

\section{Método}

Los objetivos específicos de esta investigación son:

O1. Analizar el tratamiento de la información sobre la Covid-19 en las portadas de los principales diarios informativos de España durante el primer trimestre de 2020.

O2. Identificar la representación que se ha hecho en prensa del inicio de la pandemia.

O3. Analizar la circulación de las noticias a través de las portadas como un indicador simbólico y temporal de cómo se interpreta y entiende la Covid-19.

Las hipótesis de las que parte este estudio son:

H1. El seguimiento periodístico de la pandemia en España se incrementa en la medida en que aumentan los casos de contagio.

H2. El enfoque sanitario de las portadas ha sido el más relevante frente a los enfoques económicos o políticos.

H3. La evolución en el tiempo de la pandemia ha provocado un cambio en los enfoques de las portadas.

A partir de una metodología combinada de análisis de contenido cuantitativo y cualitativo (Wimmer; Dominik, 1996; Krippendorff, 2004; Flick, 2004), se diseña un muestreo que abarca desde el 2 de enero de 2020, fecha posterior a la 
aparición del coronavirus en Wuhan (China) hasta el 31 de marzo, fecha en que termina el primer trimestre de 2020 . El 1 de enero no se ha considerado por ser una fecha excepcional periodísticamente hablando ya que ese día no hay prensa a la venta en quioscos.

El motivo de analizar el primer trimestre es corroborar la hipótesis de que el seguimiento de la pandemia en España fue ganando peso y recorrido a medida que se iba localizando en el país. Por eso se analiza desde enero (cuando no había casos en España pero sí en China), febrero (cuando irrumpe en Europa, sobre todo en Italia) y marzo cuando se siente en España, hasta la declaración del Estado de Alarma. Se han analizado un total de 630 portadas de 90 días, publicadas en 7 periódicos a lo largo del primer trimestre de 2020 (enero, febrero y marzo).

La muestra son las portadas de las ediciones impresas de los diarios:

- El país

- El mundo

- La vanguardia

- $A B C$

- El periódico

- El correo

- La razón.

Según los datos de la 1a Oleada del Estudio General de Medios (AIMC, 2020), los cuatros diarios generalistas de atención nacional con mayor número de lectores diarios son El país, El mundo, ABC y La razón. Para completar con otras cabeceras de mirada más regional, se seleccionó a La vanguardia (tercer periódico generalista con más lectores de España), El periódico (sexto) y El correo (séptimo). De esta forma también se cubría Euskadi como foco donde surgió el virus y Cataluña como una de las regiones más grandes y afectadas por la pandemia.

Estos diarios pertenecen a diferentes grupos y tendencias editoriales, por lo que los resultados posibilitan establecer dónde se encuentran las diferencias y similitudes entre ellos. Según la investigación de Nogales-Bocio y Mancinas-Chávez (2014):

- El país (Prisa) tiene un perfil socialdemócrata y representa la ideología de centro-izquierda;

- El mundo (Unidad Editorial) refiere su línea editorial con el centro-derecha;

- $A B C$ (Vocento) se identifica con el conservadurismo confesional y monárquico y se complementa con portadas llamativas;

- La razón (Planeta) posee una línea conservadora y confesional;

- La vanguardia (Godó) y El periódico (Zeta), aunque autonomistas, representan dos ejes ideológicos de Cataluña: conservador y progresista.

- El correo (Vocento) responde a un planteamiento ideológico conservador cercano a la derecha.

$A B C$ presenta el problema de que sus portadas son monográficas sobre un tema, lo que puede distorsionar la muestra. Aun así, su posición comercial y editorial hace que deba ser tenido en cuenta para un estudio de la cobertura de la Covid-19 en los periódicos españoles.

La muestra no aspira a ser una representación a escala del tratamiento informativo, sino la selección de un tema delimitado. Una vez definida, se realizó una codificación de los datos a partir de un diseño de categorías (Bardin, 2002; Sánchez-Aranda, 2005) basado en el estudio llevado a cabo por Muñiz et al. (2019), pero adaptándolo a la prensa tradicional y al objeto de estudio, lo que permitió transformar de forma sistemática los datos brutos en unidades específicas para obtener datos cuantificables y comparables y así poder llegar a conclusiones válidas (Krippendorff, 2002).

El resultado fue una plantilla de análisis compuesta por cuatro categorías para anotar todos los aspectos susceptibles de estudio.

En la primera categoría se engloban los datos de identificación, compuestos por dos subcategorías: "medio de comunicación" y "fecha de la información". Estos datos objetivos permiten identificar la portada y enmarcarla en el momento al que pertenece la información.

En la segunda categoría se incluyen datos de la jerarquización de una información en portada con las subcategorías: "texto", "fotografía", "cantidad de piezas de Covid-19 sobre el total de la portada", "noticia principal". Estos elementos también responden a criterios objetivos para determinar la importancia de una información en portada. El elemento para determinar si la pieza fue o no principal fue la colocación de la pieza a tres o cuatro columnas en la portada.

En la tercera categoría se incluyen los elementos sociopolíticos implícitos en la información, divididos en dos subcategorías: la "crítica al Gobierno" y los "contenidos socioanímicos" con algún factor motivacional.

En la cuarta categoría se analizan los encuadres en tres subcategorías. Para definirlas, se ha atendido a la organización discursiva de López-Rabadán (2010), y en concreto en las consolidadas tipologías de Entman (1993), que identifica las funciones básicas de encuadres; Eilders y Lüter (2000), que presenta como criterio la base temporal empleada; y una revisión temática de los encuadres genéricos de Semetko y Valkenburg (2000). De esta forma, el tipo de encuadre ge- 
nérico "conflicto", pasa a designarse "sanitario"; la de "consecuencias económicas", se denomina "económico" y la de "atribución de responsabilidad", pasa a nombrarse "político". Respecto a los encuadres de interés humano y moralidad, se unifican ambas cuestiones del listado original de Semetko y Valkenburg en una categoría única: "humano".

Al haber portadas con ninguna o una sola pieza, en contraposición a portadas enteras con información sobre la Covid-19, se optó por analizar las portadas como un todo y extraer el enfoque predominante sobre el mismo.

Tabla 1. Resumen protocolo de análisis de contenido

\begin{tabular}{|c|c|c|}
\hline \multirow{2}{*}{ 1. Datos e identificación } & 1.1. Medio de comunicación & \\
\hline & 1.2. Fecha de la información & \\
\hline \multirow{4}{*}{ 2. Jerarquización en portada } & 2.1. Texto & \\
\hline & 2.2. Fotografía & \\
\hline & $\begin{array}{l}\text { 2.3. Cantidad de piezas de Covid-19 sobre el total de la } \\
\text { portada }\end{array}$ & \\
\hline & 2.4. Noticia principal & \\
\hline \multirow{2}{*}{ 3. Elementos sociopolíticos implícitos } & 3.1. Crítica al Gobierno & \\
\hline & 3.2. Contenidos socioanímicos & \\
\hline \multirow{11}{*}{ 4. Framings } & \multirow{4}{*}{ 4.1. Tipología de Entman } & 4.1.1. Definición del problema \\
\hline & & 4.1.2. Diagnóstico de causas \\
\hline & & 4.1.3. Juicios o valores morales \\
\hline & & 4.1.4. Propuesta de soluciones \\
\hline & \multirow{3}{*}{ 4.2. Tipología de Eilders y Luter } & 4.2.1. Diagnóstico actual \\
\hline & & 4.2.2. Previsión de futuro \\
\hline & & 4.2.3. Motivacional \\
\hline & \multirow{4}{*}{ 4.3. Tipología de Semetko y Valkenburg } & 4.3.1. Sanitario \\
\hline & & 4.3.2. Económico \\
\hline & & 4.3.3. Político \\
\hline & & 4.3.4. Humano \\
\hline
\end{tabular}

\section{Resultados}

\subsection{Hitos, evolución y curiosidades en la cobertura de la Covid-19}

Tabla 2. Primera aparición del virus en portada

\begin{tabular}{|c|c|c|c|c|c|c|c|c|}
\hline & & \multicolumn{7}{|c|}{ Medios de comunicación } \\
\hline & & Elpaís & El mundo & $A B C$ & La razón & La vanguardia & Elperiódico & El correo \\
\hline \multirow{4}{*}{$\begin{array}{l}\text { Primera aparición del } \\
\text { virus en portada }\end{array}$} & 21 enero & $\mathbf{x}$ & & & & & & \\
\hline & 22 enero & & & & $\mathbf{x}$ & $\mathbf{x}$ & $\mathbf{x}$ & $\mathbf{x}$ \\
\hline & 23 enero & & $\mathbf{x}$ & & & & & \\
\hline & 31 enero & & & $\mathbf{x}$ & & & & \\
\hline
\end{tabular}

La portada de El país del 18 de enero informaba de que en China caía la natalidad y se frenaba la economía. Ni rastro del virus, pero sí de las primeras consecuencias que salían a flote. Sin embargo, tres días después, el 21 de enero, este medio ya incluía un breve en la sección "Salud" que titulaba: "Las claves del virus mortal que se extiende por Asia". De esta forma pasó de no ser tenido en cuenta a considerarse un "virus mortal".

Si El país fue el primero en incluir el virus en portada el 21 de enero, La vanguardia, El correo, El periódico y La razón lo hicieron al día siguiente. El mundo lo incorporó dos días después y hubo que esperar hasta el 31 de enero para ver una portada de $A B C$ con contenido sobre la Covid-19.

El 16 de enero, La vanguardia incluía una pieza sobre el aumento de casos graves y el desbordamiento de las urgencias. Es curiosa la portada de El país del 30 de enero en la que incluía una noticia sobre la soledad y el olvido de los mayores en las residencias. El 28 de febrero El país abría con “La epidemia empieza a desbordar las urgencias" y el 6 de marzo, El mundo informó en portada de los primeros contagios en geriátricos y La vanguardia habló por primera vez de síntomas en un breve: "Tos y fiebre, pero no mocos".

Si hablamos del World Mobile Congress, en las portadas de La vanguardia, El periódico y La razón del 17 de enero se podía leer que Madrid pugnaba con Barcelona por hacerse con la organización. El 23 de enero, El periódico contaba que 
finalmente se quedaba en Barcelona y el 6 de febrero ya ocupaba portadas en relación con el virus. El mundo, La vanguardia y El periódico reflejaron las primeras bajas de empresas y en los siguientes días, las distintas cabeceras las irían llevando a primera página hasta su cancelación el 13 de febrero.
El 11 de febrero la OMS anunció que Covid-19 sería el nombre oficial de la enfermedad, sin embargo, el término más utilizado en prensa fue el de "coronavirus"

El 5 de febrero, a excepción de La vanguardia, los diarios intentaban restar importancia al problema en portada. El país hablaba de censura en China, El periódico de bulos y La razón de xenofobia contra la población china.

El 16 de febrero, El país afirmaba que fue el pánico lo que llevó a suspender el Mobile, titulando: “El virus más contagioso es el miedo".

El 9 de febrero, El correo fue el primero en hablar de muertes y después, el 14 de febrero, El país y El periódico llevaron a portada la aceleración de las defunciones. El 20 de marzo comenzó la carrera de los muertos: Italia superaba a China y al día siguiente, La razón hacía hincapié en que el ritmo de muertos en Reino Unido superaba al de España. El 26 de marzo El correo y La razón señalaban que en España ya había más muertos que en China.

En la primera aparición del virus el 22 de enero todavía se le nombraba como "virus chino" o "virus de Wuhan". Como dato llamativo antes de entrar en el análisis cuantitativo, el 11 de febrero la OMS anunció que Covid-19 sería el nombre oficial de la enfermedad, sin embargo, desde entonces sólo se mencionó con esa denominación en 12 ocasiones, 2 en febrero y 10 en marzo. El término más utilizado en prensa fue el de "coronavirus".

\subsection{La cobertura de la Covid-19 en cifras}

Los datos extraídos demuestran que la información sobre la Covid-19 fue aumentando de forma progresiva (gráfico 1). Del total de portadas analizadas ( $\mathrm{N}=630), 390$ incluyeron algún contenido sobre coronavirus. De estas, el 8,1\% fueron publicadas en enero, el 20,9\% en febrero y 32,9\% en marzo. 240 portadas (38,1\%) no incluyeron ninguna información sobre el tema. El grueso de esta ausencia se encuentra en enero donde el $76,5 \%$ de las portadas publicadas en ese mes no incluyeron información alguna sobre la Covid-19.

En enero hubo tan sólo 11 días en los que al menos una de las cabeceras dedicó una parte de su portada a la información del coronavirus (del 21 al 31). En febrero, el 18 y el 21 ninguna cabecera llevó a portada información sobre la pandemia. Durante todo el mes de marzo hubo piezas en portada sobre el tema en al menos una de las cabeceras. En el $76,7 \%$ de los 90 días analizados, alguno de los periódicos incluyó algún contenido sobre el virus en portada.

En cuanto al volumen de noticias en un recorrido diacrónico (gráfico 2), en la mayor parte de los días de enero no hubo una sola pieza en portada, pasando a una media de 5 en febrero y habiendo en marzo una gran cantidad de días con más de 40.

La cobertura por periódicos fue muy pareja en cuanto al volumen de información sobre la Covid-19. La tabla 3 muestra las portadas que contuvieron alguna información relativa a la Covid-19 publicadas por cada medio en los diferentes meses.

Los que más portadas con piezas de Covid-19 publicaron sobre el total de días analizados $(\mathrm{N}=90)$ fueron $\mathrm{El}$ país y La vanguardia con un $73,3 \%$ y un $72,2 \%$ respectivamente. Les siguen $E I$ periódico $(66,7 \%)$, El correo $(65,5 \%)$ y La razón (64,4\%). A la cola están El mundo $(58,9 \%)$ y $A B C(32,2 \%)$ (tabla 3$)$.

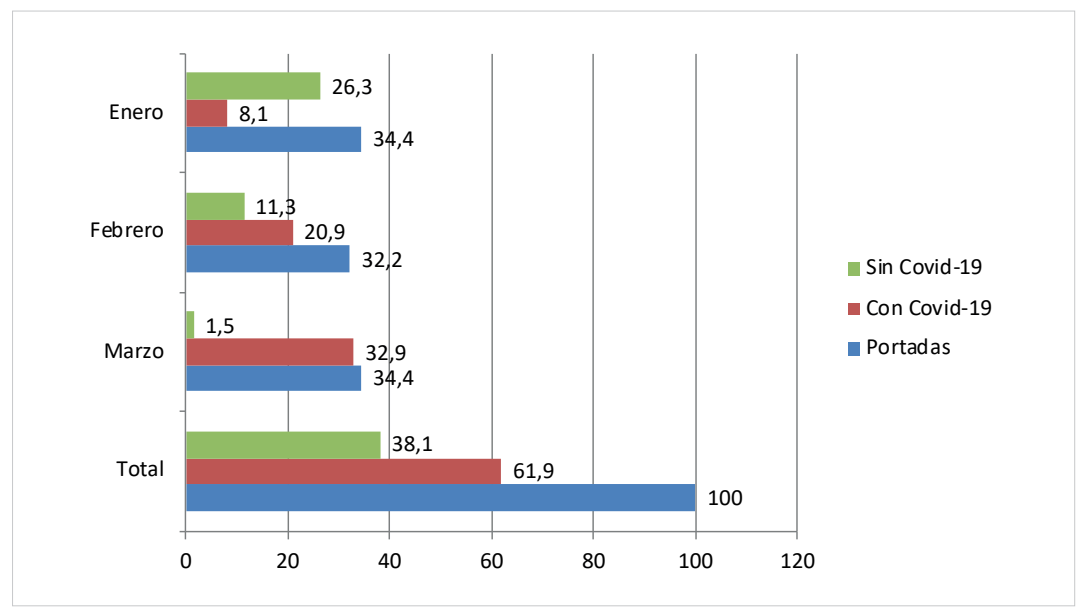

Gráfico 1. Porcentajes de portadas por meses en el primer trimestre de $2020(N=630)$

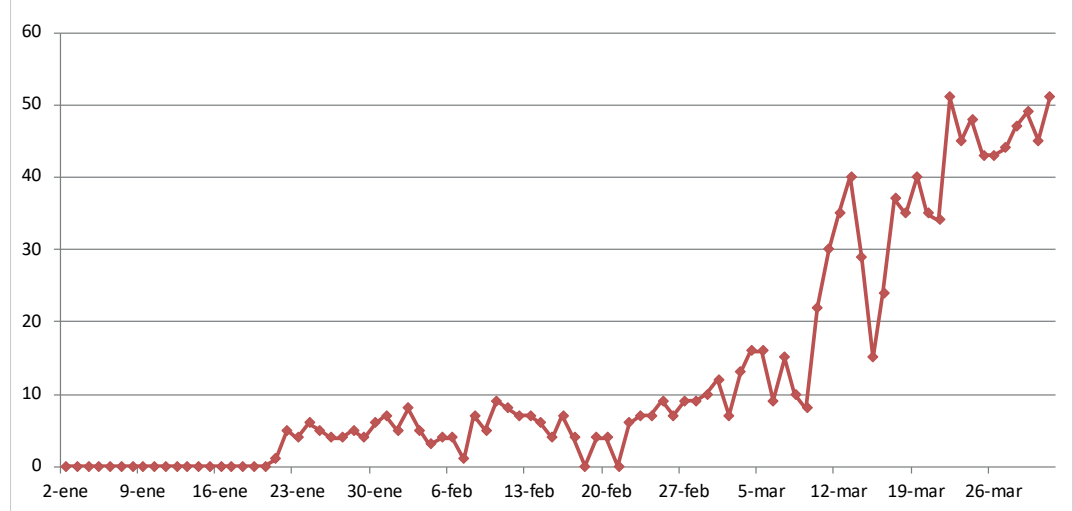

Gráfico 2. Evolución diacrónica de la cantidad de piezas sobre Covid-19 en portada 
Tabla 3. Cobertura por meses

\begin{tabular}{|c|c|c|c|c|c|c|}
\hline Cabecera & $\begin{array}{l}\text { Enero } \\
\text { (\% sobre las del } \\
\text { mes) }\end{array}$ & $\begin{array}{l}\text { Febrero } \\
\text { (\% sobre las del } \\
\text { mes) }\end{array}$ & $\begin{array}{l}\text { Marzo } \\
\text { (\% sobre las del } \\
\text { mes) }\end{array}$ & Total & $\begin{array}{l}\text { Porcentaje sobre } \\
\text { el total }(N=630)\end{array}$ & $\begin{array}{l}\text { Porcentaje sobre } \\
\text { piezas con Co- } \\
\text { vid-19 }(\mathrm{N}=390)\end{array}$ \\
\hline Elpaís & $10(33,3 \%)$ & $25(86,2 \%)$ & 31 (100\%) & 66 & 10,5 & 16,9 \\
\hline El mundo & $7(23,3 \%)$ & $15(51,7 \%)$ & 31 (100\%) & 53 & 8,4 & 13,6 \\
\hline$A B C$ & $1(3,3 \%)$ & $5(17,2 \%)$ & $23(74,2 \%)$ & 29 & 4,6 & 7,4 \\
\hline La razón & $7(23,3 \%)$ & $20(68,9 \%)$ & 31 (100\%) & 58 & 9,2 & 14,9 \\
\hline La vanguardia & $8(26,6 \%)$ & $26(89,7 \%)$ & 31 (100\%) & 65 & 10,3 & 16,7 \\
\hline Elperiódico & $8(26,6 \%)$ & $22(75,9 \%)$ & $30(96,8 \%)$ & 60 & 9,5 & 15,4 \\
\hline El correo & $10(33,3 \%)$ & $19(65,5 \%)$ & $30(98,8 \%)$ & 59 & 9,4 & 15,1 \\
\hline
\end{tabular}

Hay que tener en consideración, que la cantidad más reducida de la información en portada de $A B C$ puede provenir de que la tendencia de este periódico sea principalmente visual con una fotografía a toda página, lo que reduce el espacio para la acumulación de titulares.

Por meses (tabla 3) encontramos que en enero los periódicos que más portadas dedicaron al tema fueron El país y El correo. La alta cifra de la cabecera vasca se debe principalmente a que Euskadi fue el primer foco donde se detectaron casos del virus. Por otro lado, $A B C$ sólo dedicó una portada al tema (el 31 de enero) cuando la OMS declaró la emergencia sanitaria global.

En febrero, El país, La vanguardia y El periódico incluyeron en más del 75\% de sus portadas información sobre la Covid-19. La vanguardia tomó delantera con un $89,7 \%$ y El periódico también dio gran capacidad al tema con un $75,9 \%$. La causa de esta gran atención por parte de los medios catalanes se encuentra en que durante este mes la información sobre el World Mobile Congress que se iba a celebrar en Barcelona estuvo muy presente por el carácter local de estos medios.

$A B C$ no sólo fue el único de los periódicos que dedicó menos del $50 \%$ de sus portadas a la información sobre el coronavirus, sino que tan sólo lo hizo en 5 ocasiones, principalmente los días 23, 24 y 25 de febrero, cuando la pandemia comenzó a azotar Italia y el país decretó el cierre de fronteras y espacios públicos.

En marzo, sólo El periódico, El correo y $A B C$ no dedicaron el $100 \%$ de sus portadas a la Covid-19. El periódico fue el único que dedicó una portada entera al Día Internacional de la Mujer el 8 de marzo con una primera página morada y con el titular "Nosotras" seguido de fotos de mujeres catalanas de reconocimiento. Por su parte, El correo dedicó la portada completa del 6 de marzo a la clasificación del Athletic Club de Bilbao para la final de la Copa del Rey de fútbol.

8 de las 31 portadas de marzo de $A B C$ (del 2 al 9) no incluyeron información alguna sobre la pandemia y fueron oscilando entre las manifestaciones del sector agrícola, la salida de prisión de Oriol Junqueras y las manifestaciones del 8 de marzo.

\subsection{La Covid-19 como información principal en las portadas}

La inclusión de la Covid-19 en la primera plana fue residual hasta febrero, cuando empezó a haber más de una pieza en algunas portadas, sobre todo en La vanguardia. El 3 de marzo, el tema comenzó a ocupar la mitad de la portada de El país, pero no fue hasta el 11 de marzo, cuando empezó a instalarse asiduamente en el total de las portadas de los periódicos.

Sobre el total de portadas publicadas $(\mathrm{N}=630), 372$ portadas $(59 \%)$ no situaron a la Covid-19 como pieza principal, aunque es cierto que sólo entre enero (202) y febrero (154) ya hacen el 95,7\% de esas primeras planas donde no se priorizó al coronavirus. 258 (41\%) incluyeron como titular principal una información relacionada con la Covid-19. De estas, 8 fueron en enero (3\%), 49 en febrero (19\%) y 201 en marzo (78\%) (gráfico 3).

Por medios, comprobamos unas diferencias algo más amplias en cuanto a la información destacada en portada (tabla 4).

Resulta llamativo (tabla 4) el caso de El mundo ya que tan sólo lo situó como principal en un $47,2 \%$, menos de la mitad. Es superado incluso por $A B C$ que, aunque sólo incluyó el coronavirus en 29 de sus portadas, fue la pieza principal en 28 (un 96,5\%). Aunque hay que tener en cuenta el tipo de portada que hace $A B C$ con una o dos noticias a toda página, resulta un dato llamativo. De los diarios conservadores

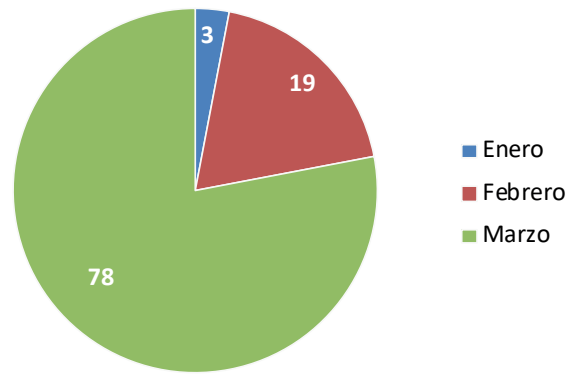

Gráfico 3. Información sobre Covid-19 como pieza principal en portada en cada mes sobre el total de portadas con Covid-19 como información destacada ( $N=258)$ 
Tabla 4. Colocación de información sobre Covid-19 como destacada por periódicos

\begin{tabular}{|c|c|c|c|c|c|c|c|}
\hline Cabecera & Enero & Febrero & Marzo & Total & $\begin{array}{l}\text { Porcentaje sobre el } \\
\text { total de portadas } \\
\text { analizadas }(\mathrm{N}=630)\end{array}$ & $\begin{array}{l}\text { Porcentaje sobre } \\
\text { piezas con Co- } \\
\text { vid-19 }(\mathrm{N}=390)\end{array}$ & $\begin{array}{l}\text { Porcentaje sobre } \\
\text { piezas con Co- } \\
\text { vid-19 del medio }\end{array}$ \\
\hline Elpaís & 3 & 10 & 30 & 43 & 6,8 & 11,0 & 65,1 \\
\hline El mundo & 0 & 3 & 22 & 25 & 3,9 & 6,4 & 47,2 \\
\hline$A B C$ & 1 & 4 & 23 & 28 & 4,4 & 7,2 & 96,5 \\
\hline La razón & 0 & 3 & 28 & 31 & 4,9 & 7,9 & 53,4 \\
\hline La vanguardia & 0 & 13 & 29 & 42 & 6,7 & 10,8 & 64,6 \\
\hline El periódico & 1 & 12 & 28 & 41 & 6,5 & 10,5 & 68,3 \\
\hline El correo & 3 & 6 & 28 & 37 & 5,9 & 62,7 & 62,7 \\
\hline
\end{tabular}

nacionales, La razón fue el que más veces otorgó un espacio preferente a la Covid-19 con una frecuencia algo superior a la mitad (53,4\%).

De estos datos se desprende que los periódicos nacionales de tendencia conservadora (El mundo, ABC y La razón) fueron más reticentes a otorgar un espacio destacado a la Covid-19 durante los dos primeros meses y que no fue hasta su expansión dentro de las fronteras españolas cuando empezaron a considerarlo como tema principal.

\subsection{Las fotografías de portada sobre la Covid-19}

De las 630 portadas analizadas, 227 (36\%) incluyeron algún tipo de fotografía relacionada con la Covid-19 y 403 (64\%) no incluyeron ninguna. De las 227 , en 187 la propia fotografía fue la imagen principal de la portada, lo que supone un $29,7 \%$ sobre el total de las portadas, un $47,9 \%$ sobre las que incluían algún contenido de coronavirus, y un $82,4 \%$ entre las que llevaban fotografía relacionada con el tema. 19 fueron publicadas en enero $(3 \%), 51$ en febrero $(8,1 \%)$ y 157 en marzo $(24,9 \%)$. De las 19 portadas de enero, 10 fueron fotografía principal $(52,6 \%)$; de las 51 del mes de febrero, $40(78,4 \%)$ y de las 157 de marzo, 137 (87,3\%). Sobre las portadas que incluyeron alguna pieza sobre el coronavirus ( $\mathrm{N}=390$ ), más de la mitad, el 58,2\%, llevaba también fotografía. De estas 390, un $47,9 \%$ fueron la imagen principal.

En 51 fotografías principales apareció una mascarilla, sobre todo llevadas por personas asiáticas. A partir de los confinamientos en los distintos países, fue una constante la fotografía de calles vacías. Hasta 14 veces una calle sin gente fue portada, siendo La vanguardia (5) y EI periódico (4) los que más veces recurrieron a esta imagen.

Los colectivos profesionales que más aparecieron en portadas fueron el personal sanitario (16), policías (8) y militares (7), pero principalmente fue en marzo cuando tuvieron espacio en portada. En cuanto a políticos, el que más veces apareció fue Pedro Sánchez (12), aunque

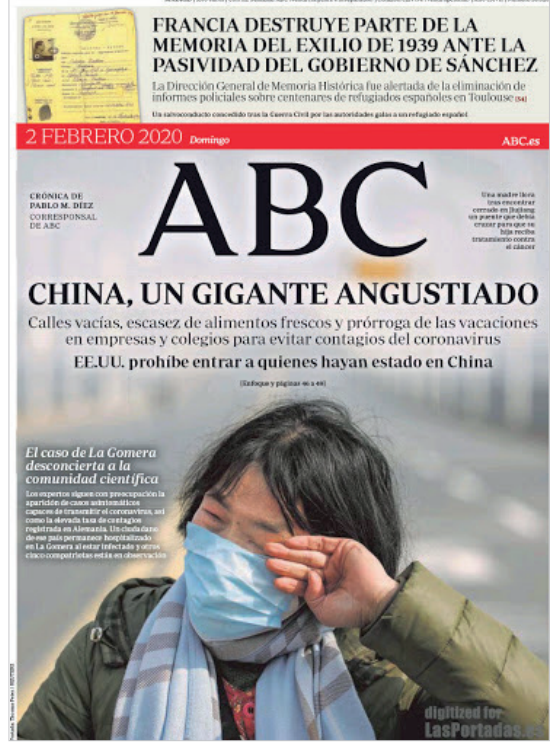

Imagen 1. Portada $A B C$ (2 febrero 2020)
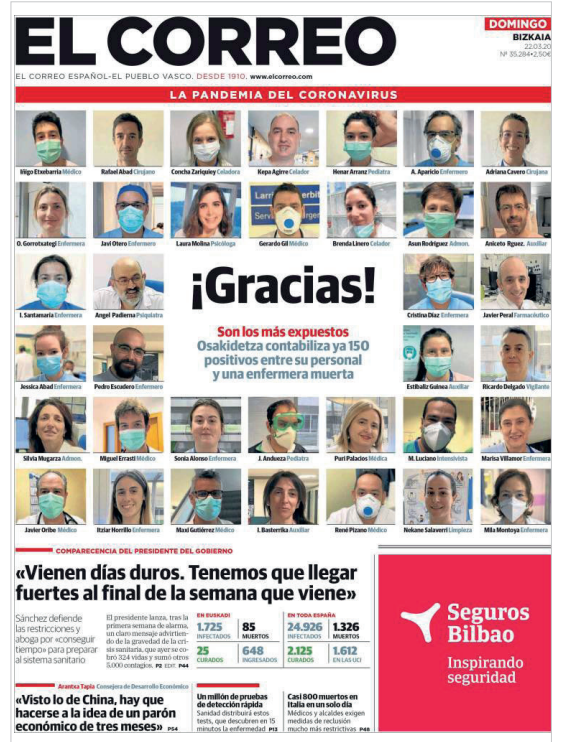

Imagen 3. Portada El correo (22 marzo 2020)

\section{LAVANGUARDIA}

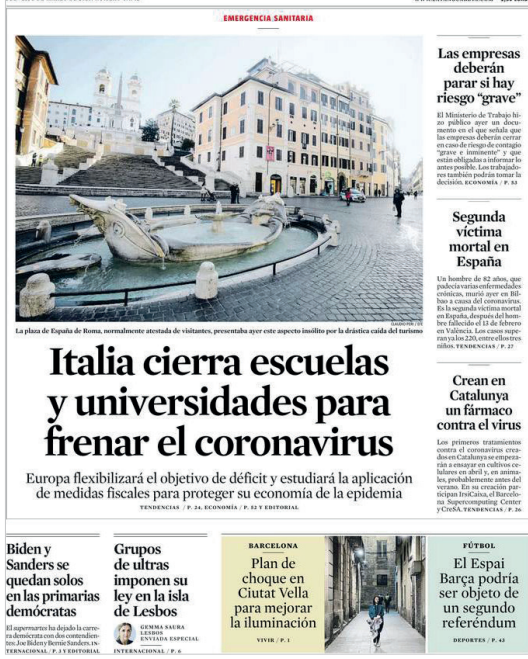

Imagen 2. Portada La vanguardia (5 marzo 2020)

\section{EL PAIS}

Ni:

spaña, en emergencia

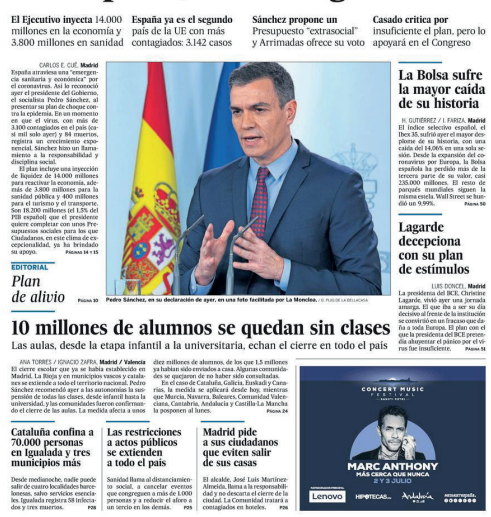

Imagen 3. Portada El correo (22 marzo 2020) 
todas en marzo. El país fue el que más veces colocó una foto del Presidente en portada (5) y todas ellas fueron durante una comparecencia pública o una videoconferencia con el Consejo de Ministros.

Resulta curioso que la segunda personalidad política con más apariciones sea el Rey de España, todas en marzo. Estas fotografías principales coinciden en el 19 de marzo cuando se emitió el discurso del monarca a la nación sobre la pandemia; y el 27 de marzo cuando visitó el hospital improvisado de Ifema. Es llamativo que los cuatro diarios nacionales ( $E$ I país, El mundo, $A B C$ y La razón) lo situaron como fotografía principal de portada, mientras que La vanguardia, El periódico y El correo, de corte regionalista, no lo hicieron.
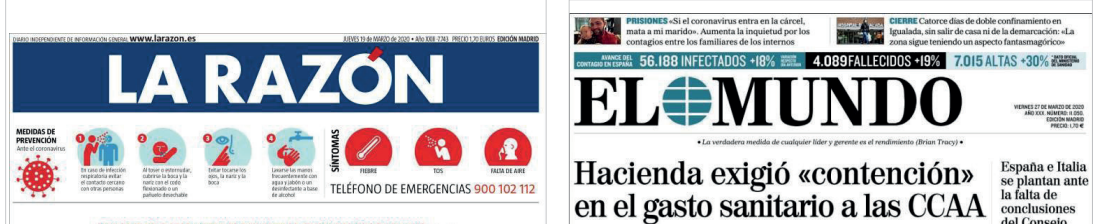

Hacienda exigió «contención»" $\begin{gathered}\text { Espana e etalia } \\ \text { se plantananante }\end{gathered}$ en el gasto sanitario a las CCAA

«Lo superaremos juntos»

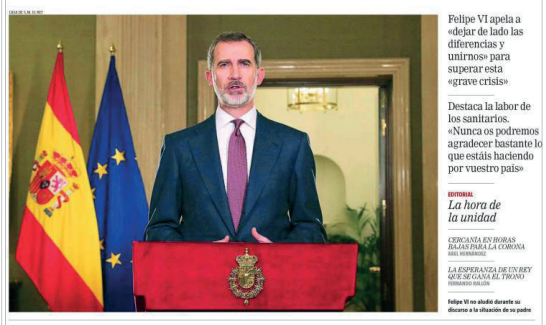

Sánchez pierde la legislatura: sus socios evidencian la ruptura en el Congreso

Alarma en las residencias de

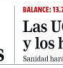

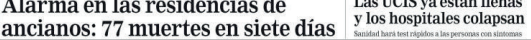

Imagen 5. Portada La razón (19 marzo 2020)
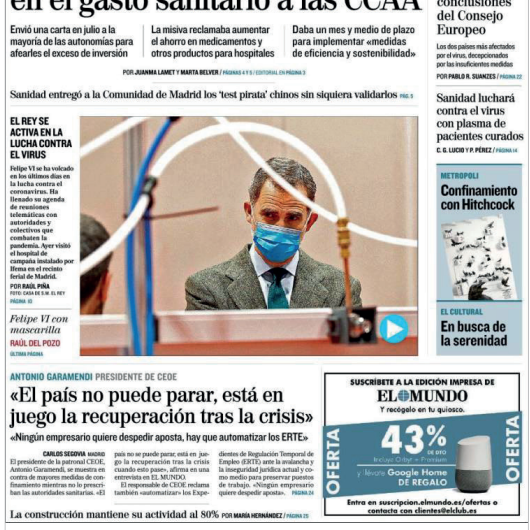

Imagen 6. Portada El mundo (27 marzo 2020)

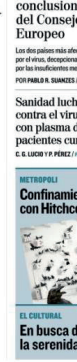

\subsection{Los encuadres de la cobertura en portada sobre la Covid-19}

Respecto a las funciones clásicas de encuadre señaladas por Entman (1993), se detecta que al hablar de la Covid-19 las que más se cumplen son las de "definición del problema" (32,6\%) y "propuesta de soluciones" (37,2\%) sobre el total de portadas que incluyeron coronavirus ( $\mathrm{N}=390)$ (gráfico 4). El seguimiento de la pandemia osciló entre la descripción del avance del virus y sus consecuencias y, por otro lado, las propuestas de soluciones sanitarias y económicas.

En enero y febrero, período de expansión de la Covid-19, se comprueba cómo todavía dominaba el encuadre de la definición, mientras que en marzo ganó más peso el de la propuesta de soluciones (gráfico 5).

Los "juicios o valoraciones morales" no tuvieron una posición demasiado relevante en las portadas sobre la Covid-19 (7,4\%) (gráfico 4 ), aunque es cierto que en marzo (gráfico 5) afloraron en gran medida preponderando este encuadre en el $11,1 \%$ del total de las portadas de ese mes cuando en enero y febrero había supuesto un 0 y un $4,5 \%$. Cuando el virus penetró en España, se hicieron más habituales, aunque fueron principalmente las cabeceras de tendencia conservadora a nivel nacional ( $E I$ mundo, $A B C$, La razón) los que enfocaron más portadas en este encuadre. El $34,8 \%$ de las portadas de $A B C$, el $29 \%$ de las de La razón y el $16,1 \%$ de las portadas de El mundo en marzo, tuvieron como encuadre principal los juicios morales (tabla 5).

En cuanto a la tipología de Eilders y Lüter (2000) comprobamos que el encuadre más recurrente en las cabeceras analizadas es el de "Diagnóstico actual" (93,1\% de los casos) frente a una presencia mucho más minoritaria de aquellas que realizaron una "previsión de futuro" $(3,3 \%)$, o adoptaron una perspectiva más "motivacional" (2,8\%) (gráfico 6).

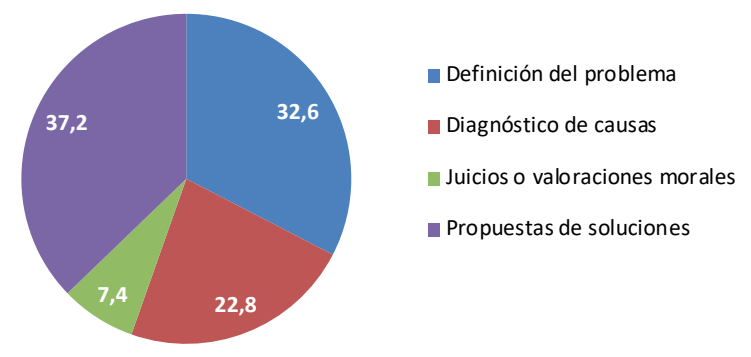

Gráfico 4. Porcentaje categorías “Encuadre Entman”

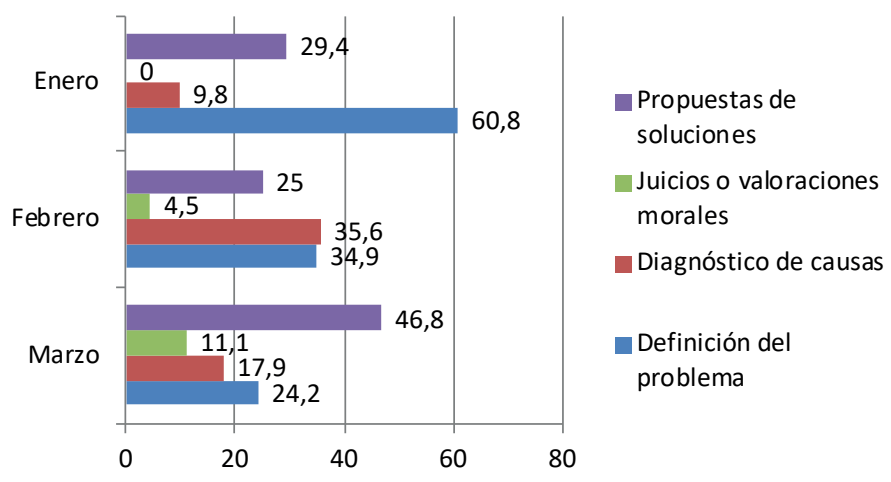

Gráfico 5. Porcentaje categorías “Encuadre Entman” por meses 
Tabla 5. Tipología Entman por medios durante el mes de marzo

\begin{tabular}{|l|c|c|c|}
\cline { 2 - 4 } \multicolumn{1}{c|}{ Cabecera } & \multicolumn{3}{c|}{ Tipología Entman } \\
\hline El país & Definición del problema & Diagnóstico de causas & $\begin{array}{c}\text { Juicios o valoraciones } \\
\text { morales }\end{array}$ \\
\hline El mundo & $8(25,8 \%)$ & $9(29,0 \%)$ & $0(0 \%)$ \\
\hline ABC & $9(29,0 \%)$ & $5(16,1 \%)$ & $5(16,1 \%)$ \\
\hline La razón & $6(26,1 \%)$ & $1(4,3 \%)$ & $8(34,8 \%)$ \\
\hline La vanguardia & $7(22,6 \%)$ & $5(16,1 \%)$ & $9(29,0 \%)$ \\
\hline El periódico & $6(19,4 \%)$ & $8(25,8 \%)$ & $0(0 \%)$ \\
\hline El correo & $6(20,0 \%)$ & $6(20,0 \%)$ & $12(38,7 \%)$ \\
\hline
\end{tabular}

Un 15,4\% de las portadas con contenido sobre Covid-19 ( $\mathrm{N}=390)$ incluyeron algún elemento socio-anímico. La mayoría se centró en el apoyo al personal sanitario, el ánimo asociado a resistir, las cosas que se pueden hacer en casa durante la cuarentena y las ayudas altruistas. También hay que destacar que el 15 de marzo, El país, El mundo, La vanguardia, $A B C$ y $L a$ razón abrieron con la campaña del Gobierno para incentivar las medidas de distanciamiento social: "Este virus lo paramos unidos".

La razón fue el medio que más resaltó los elementos socio-anímicos, lanzando además una campaña propia "Yo resistiré por ti" en la que ponía en valor la resistencia y el bien común. También en el plano regional, El correo y La vanguardia incluyeron alguno en sus portadas. El correo las centró principalmente en el apoyo a los sanitarios llegando a hacer el 22 de marzo una portada a toda página con fotografías del personal en hospitales vascos bajo el titular "Gracias". La vanguardia incluyó una miscelánea de estos elementos pero resulta llamativo cómo el 4 de marzo todavía titulaban: "No evitemos los besos ni los saludos".

Respecto a los encuadres temáticos que hemos propuesto basados en la tipología de Semetko y Valkenburg (2000) (gráfico 7), el enfoque hegemónico fue el "sanitario" (61,5\% de las portadas con alguna pieza sobre la Covid-19). Por detrás encontramos el "económico" $(24,4 \%)$, el "humano" (7,4\%) y el "político" (6,7\%).

En enero, las portadas con enfoque principalmente sanitario fueron el $80,4 \%$, en febrero el $59,1 \%$ y en marzo el $58,5 \%$ (gráfico 8 ). El aspecto económico fue ganando peso según avanzaba la pandemia. De ser meramente circunstancial en enero (7,8\%), pasó a suponer el $33,3 \%$ en febrero y el $22,7 \%$ en marzo. El pico de febrero se dio cuando el virus todavía no era considerado como una amenaza real, pero afectaba a las bolsas por el pánico de los mercados. En marzo mantuvo la atención por las medidas a tomar para paliar la incidencia del confinamiento sobre la economía.

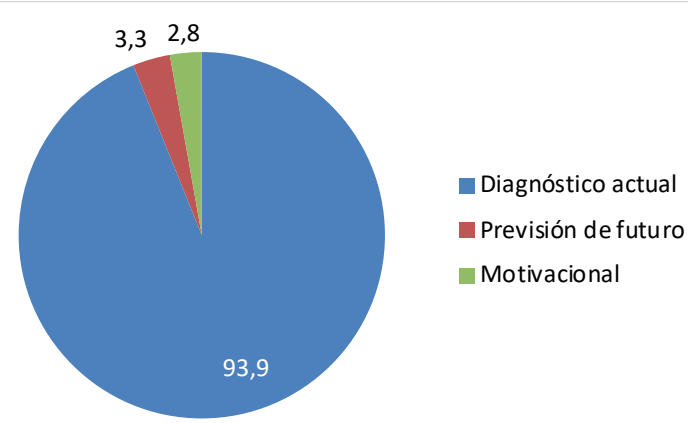

Gráfico 6. Porcentaje categorías "Encuadre Eilders y Lüter"

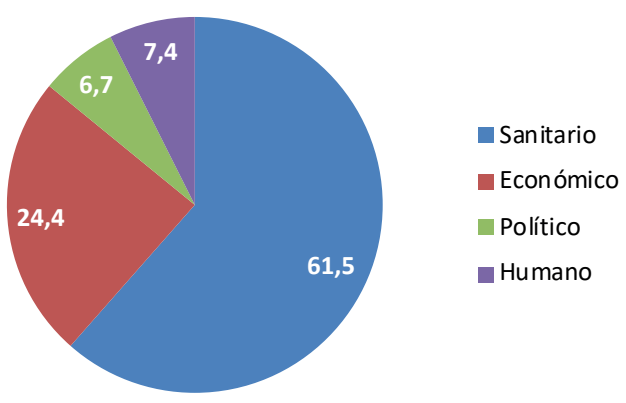

Gráfico 7. Porcentaje categorías "Encuadre Semetko y Valkenburg"

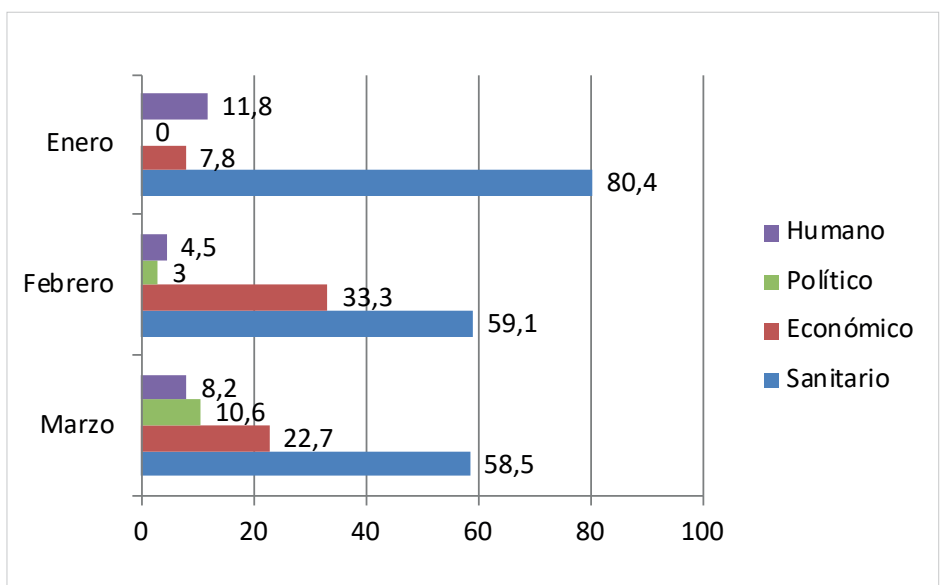

Gráfico 8. Porcentaje categorías "Encuadre Semetko y Valkenburg" por meses 
El enfoque político apareció en marzo, cuando el virus ya afectaba a España y el Gobierno tenía que tomar decisiones. Mientras el total de portadas con encuadre político sólo supuso un 6,7\% del total (gráfico 7), sobre las del mes de marzo fueron un 10,6\%. Esto indica que la mayor parte de las portadas con encuadre político se dieron en este mes. El encuadre humano primó en un 7,4\% de las portadas (gráfico 7) siendo bastante parecida su distribución por meses.

Por medios, encontramos algunas diferencias destacables como es la gran atención de los diarios catalanes (La vanguardia y El periódico) al encuadre económico, un 38,5\% y un 31,7\% de las portadas respectivamente, muy por encima de los primeros nacionales, El país $(24,2 \%)$ y $A B C(20,7 \%)$.

Tabla 6. Cantidad de piezas y porcentaje sobre el total de las portadas con Covid-19 por medios de comunicación

\begin{tabular}{|l|c|c|c|}
\cline { 2 - 4 } \multicolumn{1}{c|}{} & \multicolumn{3}{c|}{ Tipología Semetko y Valkenburg } \\
\hline El país & Sanitario & Económico & Político \\
\hline El mundo & $45(69,2 \%)$ & $16(24,6 \%)$ & $1(1,5 \%)$ \\
\hline ABC & $30(56,6 \%)$ & $14(26,4 \%)$ & $5(9,4 \%)$ \\
\hline La razón & $12(41,4 \%)$ & $6(20,7 \%)$ & $8(27,6 \%)$ \\
\hline La vanguardia & $33(56,9 \%)$ & $9(15,5 \%)$ & $10(17,2 \%)$ \\
\hline El periódico & $34(52,3 \%)$ & $25(38,5 \%)$ & $1(1,5 \%)$ \\
\hline El correo & $38(63,3 \%)$ & $19(31,7 \%)$ & $1(1,7 \%)$ \\
\hline
\end{tabular}

Los medios conservadores nacionales dieron más relevancia al encuadre político. El 27,6\% de las portadas de $A B C$ tuvieron esta tipología como encuadre principal, La razón un 17,2\% y El mundo un $9,4 \%$. Si los comparamos con el resto la diferencia es muy grande ya que ninguno dedicó más de un $2 \%$. Además, fue en marzo cuando la política empezó a centrar su atención con un 34,8\% de las portadas de ese mes de ABC, un 29\% La razón y un 12,9\% El mundo.

Tabla 7. Portadas que incluían crítica al Gobierno por medios

\begin{tabular}{|c|c|c|c|c|}
\hline \multirow[b]{2}{*}{ Cabecera } & \multicolumn{4}{|c|}{ Crítica al gobierno } \\
\hline & Enero & Febrero & Marzo & Total \\
\hline El país & 0 & 0 & 5 & $5(7,7 \%)$ \\
\hline El mundo & 0 & 0 & 18 & $18(30,5 \%)$ \\
\hline$A B C$ & 0 & 0 & 14 & $14(48,3 \%)$ \\
\hline La razón & 1 & 1 & 21 & $23(39,0 \%)$ \\
\hline La vanguardia & 0 & 1 & 3 & $4(6,2 \%)$ \\
\hline El periódico & 0 & 0 & 1 & $1(1,7 \%)$ \\
\hline El correo & 0 & 0 & 7 & $7(11,9 \%)$ \\
\hline $\begin{array}{l}\text { Total sobre piezas con } \\
\text { Covid-19 }(\mathrm{N}=390)\end{array}$ & 1 & 2 & 69 & $72(18,5 \%)$ \\
\hline
\end{tabular}

Esto tiene que ver con el grado de crítica al Gobierno, que encontró en marzo su pico más elevado. Sobre el total de portadas con información sobre la pandemia, un 18,5\% incluyeron crítica explícita al Gobierno de España, pero el 93,2\% de estas fueron en marzo. Los medios conservadores nacionales fueron los más beligerantes, dedicando $A B C$, un $48,3 \%$ de sus portadas a la crítica contra el Gobierno, La razón un 39\% y El mundo un 30,5\%. El correo incluyó crítica en un $11,9 \%$ de sus portadas, El país en un 7,7\% y La vanguardia en un 6,2\%. Destaca la casi inexistente beligerancia por parte de $E I$ periódico, dedicando apenas un 1,7\% a la crítica contra la gestión del Gobierno.

\section{Conclusiones}

Podemos establecer una serie de conclusiones sobre el tratamiento informativo de la prensa española sobre la Covid-19 en el primer trimestre de 2020.

Se comprueba que pese a que el 11 de febrero la OMS nombró oficialmente al virus como Covid-19, la prensa no utilizó esa denominación y optó por la de "coronavirus". Además, hubo un interés primigenio en cuanto a los términos de alejar al virus de la proximidad. Las primeras denominaciones fueron "coronavirus chino" o "virus de Wuhan", otorgándole una nacionalidad y cerrando la puerta a considerar una pandemia global.

El enfoque político apareció en marzo, cuando el virus ya afectaba a España y el Gobierno tenía que tomar decisiones 
Se detecta un progresivo aumento del interés en el tema directamente relacionado con su proximidad. En la primera veintena de enero la Covid-19 fue invisible pese a que ya estaba muy extendido en China. A medida que la pandemia llegaba a Europa (febrero) y se extendía en España (marzo), las primeras páginas le fueron dando más importancia hasta copar espacios enteros en portada. Smith et al. (2013) detectan que la cobertura periodística se incrementa a partir de la detección del primer caso en el país, lo cual se cumple con la de la Covid-19. El primer caso en España apareció en prensa el 1 de febrero. La atención en portada de la pandemia comenzó a aumentar a partir de principios de febrero y en marzo el virus se hizo omnipresente.

La Covid-19 como acontecimiento informativo extraordinario ha saltado esquemas que la prensa española seguía durante dos décadas. La homogeneización temática que se situaba en un $25,5 \%$ en la evolución de las portadas de prensa de 1990-2010 (López-Rabadán; Casero-Ripollés, 2014), se sitúa en un 61,9\% en el primer trimestre de 2020. El país fue el medio en el que la presencia de la Covid-19 en portada fue más uniforme. El más dicotómico fue El mundo, ya que en marzo dedicó portadas completas con dos decenas de piezas sobre el virus y apenas resaltó información relativa al mismo en enero y febrero.

La atención a la Covid-19 se centró en el enfoque sanitario y en el diagnóstico actual. También en los encuadres, la pandemia se ha salido de los moldes. La cobertura en décadas pasadas en España se centraba en el diagnóstico de causas y los juicios morales, dejando de lado la propuesta de soluciones. Sin embargo, los encuadres más extendidos del coronavirus fueron precisamente el de la definición del problema y la propuesta de soluciones. El poco conocimiento sobre la pandemia llevó a eludir en gran medida el diagnóstico de causas y, en un primer momento se intentó eludir los juicios para después darles mayor importancia.

El encuadre político, al igual que ocurre con los juicios morales, llegó con las medidas y soluciones. Se hizo política con la Covid-19, cuando el problema ya estaba encima y no antes. Los medios conservadores editorializaron en mayor medida sus portadas con la crítica al Gobierno, mientras que los de centroizquierda y relativa izquierda apoyaron críticamente las medidas del Gobierno.

El eje temporal muestra de forma clara que enero fue el mes de la definición del problema, febrero el del diagnóstico de las causas y marzo el de la propuesta de las soluciones. Se puede hablar incluso de dos tratamientos informativos muy diferentes que hemos nombrado como "Estado de pre-alarma" (antes del 14 de marzo) y "Estado de alarma" (después del 14 de marzo). Durante el primero la información sobre el virus era residual, discontinua y a menudo restando importancia al problema. Eran muy pocos los contenidos que relacionaban el tema con España y se veía al coronavirus como una enfermedad china muy alejada del rango internacional.

A partir del segundo, toda portada incluyó algún elemento relacionado con la pandemia, llegando a ocupar primeras planas al completo. La importancia pasó a ser máxima y la información se centró casi al completo en España. Además, comenzaron a aparecer portadas con contenido socio-anímico y cifras sobre la Covid-19, pero la prevalencia actual de la Covid-19 y la incertidumbre del futuro hicieron que la presencia de elementos motivacionales en portada fuera escasa.

En marzo, la pandemia cambió incluso la forma de confeccionar portadas, llegando a encontrar primeras páginas de EI mundo o El país con más de 10 noticias en portada. El mundo incluyó hasta 20 el 22 de marzo.

Como propuesta o línea futura, sería conveniente continuar el análisis con 2020 al completo para comprobar el avance de la cobertura y los encuadres según vaya remitiendo la pandemia. También podrían analizarse las coberturas en otros medios como televisión, radio o digitales para poder comparar las coberturas según el soporte. Además de este análisis de contenido, sería necesario completar con etnografías de agencias de noticias o entrevistas en profundidad con periodistas para abordar más profundamente las diferentes coberturas informativas y editoriales de las portadas. Este primer intento de identificar patrones de la cobertura de la Covid-19 a través de la página principal puede establecer una base para construir en el futuro investigaciones sobre el tema.

\section{Referencias}

AIMC (2020). Resumen de la primera oleada del Estudio general de medios 2020. Asociación para la Investigación de Medios de Comunicación (AIMC).

https://www.aimc.es/blog/entrega-resultados-egm-1a-ola-2020

Bardin, Laurence (2002). El análisis de contenido. Madrid: Akal. ISBN: 9788476000939

Bryant, Jennings; Miron, Dorina (2004). "Theory and research in mass communication". Journal of communication, v. 54, n. 4, pp. 662-704.

https://doi.org/10.1111/j.1460-2466.2004.tb02650.x 
Canales, Laura; Lizárraga, Frambel (2019). “La agenda mediática sobre inmigración en las portadas de El universal, La jornada y La opinión durante la administración de Donald Trump”. Interdisciplina, v. 7, n. 18, pp. 149-165. https://doi.org/10.22201/ceiich.24485705e.2019.18.68978

Cantrell-Rosas-Moreno, Tania; Harp, Dustin; Bachmann, Ingrid (2013). “Encuadre de ideologías: Cómo la revista Time representa el nacionalismo y las identidades en sus portadas". Comunicación y sociedad, v. 26, n. 3, pp. 1-20. https://revistas.unav.edu/index.php/communication-and-society/article/view/36075

Casero-Ripollés, Andreu (2020). "Impact of Covid-19 on the media system. Communicative and democratic consequences of news consumption during the outbreak". El profesional de la información, v. 29, n. 2, e290223. https://doi.org/10.3145/epi.2020.mar.23

D’Angelo, Paul (2002). "News framing as a multiparadigmatic research program: A response to Entman". International Communication Association, v. 52, n. 4, pp. 870-888. https://doi.org/10.1111/j.1460-2466.2002.tb02578.x

De-Vreese, Claes H. (2005). “News framing: Theory and typology". Information design journal + document design, v. 13, n. 1, pp. 51-62. https://claesdevreese.files.wordpress.com/2015/09/devreese_2005_2.pdf

Donohue, Thomas R.; Glasser, Theodore L. (1978). "Homogeneity in coverage of Connecticut newspapers". Journalism quarterly, v. 55, n. 3, pp. 592-595.

https://doi.org/10.1177/107769907805500328

Eilders, Christiane; Lüter, Albrecht (2000). "Research note: Germany at war. Competing framing strategies in German public discourse". European journal of communication, v. 3 n. 15, pp. 415-428. https://doi.org/10.1177/0267323100015003009

Entman, Robert M. (1993). "Framing: toward clarification of a fractured paradigm". Journal of communication, v. 43, n. 4, pp. 51-58. https://doi.org/10.1111/j.1460-2466.1993.tb01304.x

European Commission (2017). Media use in the European Union. Standard Eurobarometer 88. Brussels: European Commission. ISBN: 9789279809835

https://op.europa.eu/en/publication-detail/-/publication/a575c1c9-58b6-11e8-ab41-01aa75ed71a1

Faridah, Ibrahim; Normah, Mustaffa; Chang, Peng (2010). "Framing a pandemic: Analysis of Malaysian mainstream newspapers in the H1NI coverage". Journal of media and information warfare, v. 3, pp. 105-122.

http://ir.uitm.edu.my/id/eprint/10948

Farré-Coma, Jordi (2005). “Comunicación del riesgo y espirales del miedo". Comunicación y sociedad, v. 2, n. 3, pp. $95-119$. https://www.doi.org/10.32870/cys.v0i3.4209

Flick, Uwe (2004). Introducción a la investigación cualitativa. Madrid: Morata. ISBN: 9788471124807

Gitlin, Todd (1980). The whole world is watching: Mass media in the making and unmaking of the new left. Berkeley: University of California Press. ISBN: 9780520239326

Hallin, Daniel C.; Briggs, Charles L.; Mantini-Briggs, Clara; Spinelli, Hugo; Sy, Anahi (2020). "Mediatización de las pandemias: la cobertura sobre la pandemia de la gripe A (H1N1) de 2009 en Argentina, Estados Unidos y Venezuela". Comunicación y sociedad, v. 17, pp. 1-24.

https://doi.org/10.32870/cys.v2020.7207

Havas Media Group España (2020). Impacto del coronavirus en hábitos y medios. Madrid: Havas Group. https://bit.ly/2zOcOFO

Herranz-de-la-Casa, José-María; Cantero-de-Julián, Juan-Ignacio (2019). "El tratamiento informativo de los colectivos vulnerables en los medios de comunicación. ¿Veracidad, desinformación o estereotipos?”. En: Gómez-Cirano, Emilio-José (coord.). Imagen, estigma y derechos humanos: Claves para abordar la vulnerabilidad y la exclusión desde el trabajo social y la comunicación, pp. 29-62. Tirant lo Blanch. ISBN: 9788413365121

Hornmoen, Harald; Backholm, Klas (2018). Social media use in crisis and risk communication: Emergencies, concerns and awareness. Londres: Emerald Group Publishing. ISBN: 9781787562721.

Idoyaga, Nahia; Valencia, José-Francisco; Gil-de-Montes, Lorena; Ortiz, Garbiñe (2012). "Efectos del framing y representaciones sociales de epidemias sanitarias: el caso de la gripe A". Escritos de psicología, v. 5, n. 3, pp. 31-42. https://doi.org/10.5231/psy.writ.2012.0211

Igartua-Perosanz, Juan-José; Humanes, María Luisa (2004). Teoría e investigación en comunicación social. Madrid: Síntesis. ISBN: 8497562267 
Koziner, Nadia S. (2013). "Antecedentes y fundamentos de la teoría del framing en comunicación”. Austral comunicación, v. 2, n. 1, pp. 1-25.

https://doi.org/10.26422/aucom.2013.0201.koz

Krippendorff, Klaus H. (2002). Metodología del análisis de contenido. Teoría y práctica. Barcelona: Paidós. ISBN: 97884 75096278

Krippendorff, Klaus H. (2004). Content analysis: An introduction to its methodology. Thousand Oaks, Calif.: Sage. ISBN: 9780761915447

Lecheler, Sophie; De-Vreese, Claes H. (2012). “News framing and public opinion: A mediation analysis of framing effects on political attitudes". Journalism \& mass communication quarterly, v. 89, n. 2, pp. 185-204.

https://doi.org/10.1177/1077699011430064

López-Rabadán, Pablo (2010). "Nuevas vías para el estudio del framing periodístico. La noción de estrategia de encuadre". Estudios sobre el mensaje periodístico, v. 16, pp. 235-258.

https://revistas.ucm.es/index.php/ESMP/article/view/ESMP1010110235A

López-Rabadán, Pablo; Casero-Ripollés, Andreu (2014). “La información periodística de portada en España: evolución histórica de fuentes, agendas y encuadres (1980-2010)”. Historia y comunicación social, v. 19, n. 1, pp. 457-473.

https://doi.org/10.5209/rev_hics.2014.v19.44977

Lubens, Pauline (2015). "Journalists and public health professionals: Challenges of a symbiotic relationship". Disaster medicine and public health preparedness, v. 9, n. 1, pp. 59-63.

https://doi.org/10.1017/dmp.2014.127

Major, Ann M.; Atwood, L. Erwin (2004). "Environmental risks in the news: Issues, sources, problems and values". Public understanding of science, v. 13, n. 3, pp. 295-308.

https://doi.org/10.1177/0963662504044557

Masip, Pere; Aran-Ramspott, Sue; Ruiz-Caballero, Carlos; Suau, Jaume; Almenar, Ester; Puertas-Graell, David (2020). "Consumo informativo y cobertura mediática durante el confinamiento por el Covid-19: sobreinformación, sesgo ideológico y sensacionalismo". El profesional de la información, v. 29, n. 3, e290312.

https://doi.org/10.3145/epi.2020.may.12

Matthes, Jörg (2012). “Framing politics: An integrative approach”. American behavioral scientist, v. 56, n. 3, pp. $247-259$. https://doi.org/10.1177/0002764211426324

McCombs, Maxwell E. (2005). “A look at agenda-setting: Past, present and future”. Journalism studies, v. 6, n. 4, pp. $543-557$. https://doi.org/10.1080/14616700500250438

McCombs, Maxwell E.; Shaw, Donald L. (1972). "The agenda-setting function of the mass media". Public opinion quarterly, v. 36, n. 2, pp. 176-187.

https://doi.org/10.1086/267990

Meisner, Mark S.; Takahashi, Bruno (2013). “The nature of Time: How the covers of the world's most widely read weekly news magazine visualize environmental affairs". Environmental communication, v. 7, n. 2, pp. 255-276.

https://doi.org/10.1080/17524032.2013.772908

Muñiz, Carlos (2015). "La política como debate temático o estratégico. Framing de la campaña electoral mexicana de 2012 en la prensa digital”. Comunicación y sociedad, v. 12, n. 23, pp. 67-95.

https://doi.org/10.32870/cys.v0i23.64

Muñiz, Carlos; Campos-Domínguez, Eva; Saldierna, Alma-Rosa; Dader, José-Luis (2019). “Engagement of politicians and citizens in the cyber campaign on Facebook: a comparative analysis between Mexico and Spain". Contemporary social science, v. 14, n. 1, pp. 102-113.

https://doi.org/10.1080/21582041.2017.1367832

Nielsen, Rasmus-Kleis; Fletcher, Richard; Newman, Nic; Brennen, J. Scott; Howard, Philip N. (2020). Navigating the 'infodemic': How people in six countries access and rate news and information about coronavirus. UK: The Reuters Institute for the Study of Journalism \& University of Oxford. ISBN: 9781907384745

https://bit.ly/2SNhNN3

Niemeyer, Katharina (2019). "The front page as a time freezer: An analysis of the international newspaper coverage after the Charlie Hebdo attacks". Media, war \& conflict, v. 12, n. 2, pp. 187-201.

https://doi.org/10.1177/1750635219839378

Nogales-Bocio, Antonia-Isabel; Mancinas-Chávez, Rosalba (2014). “Los diarios de referencia en el mercado de la prensa española. Propiedad, grupos mediáticos y conexiones estructurales”. Correspondencias y análisis, n. 4, pp. 307-333.

http://hdl.handle.net/11441/32644 
Park, Sejin; Boatwright, Brandon; Avery, Elizabeth-Johnson (2019). “Information channel preference in health crisis: Exploring the roles of perceived risk, preparedness, knowledge, and intent to follow directives". Public relations review, v. 45, n. 5.

https://doi.org/10.1016/j.pubrev.2019.05.015

Pérez-Curiel, Concha; Jiménez-Marín, Gloria; García-Medina, Irene (2020). "Influencia de agendas y estudio de framing en el marco electoral del Procés de Cataluña". Revista latina de comunicación social, v. 75, pp. 27-51.

https://doi.org/10.4185/RLCS-2020-1415

Peris-Vidal, Manuel (2018). “El tratamiento periodístico del partido político Podemos en El País y Público: un análisis desde la teoría del framing". Vivat academia, n. 143, pp. 111-134.

https://doi.org/10.15178/va.2018.143.111-134

Peterson, Tarla R.; Thompson, Jessica L. (2009). “Environmental risk communication: Responding to challenges of complexity and uncertainty”. In: Heath, Robert L.; O'Hai, H. Dan (eds.). Handbook of risk and crisis communication. NY: Routledge, pp. 591-606. ISBN: 9780805857771

Reese, Stephen D. (2001). "Framing public life: A bridging model for media research". In: Reese, Stephen D.; Gandy, Oscar H.; Grant, August E. (eds.). Framing public life: Perspectives on media and our understanding of the social world. Mahwah, New Jersey: Lawrence Erlbaum Associates, pp. 7-32. ISBN: 0805836535

Riffe, Daniel; Shaw, Eugene F. (1982). "Conflict and consonance: Coverage of third world in two US papers". Journalism quarterly, v. 59, n. 4, pp. 617-626. https://doi.org/10.1177/107769908205900414

Rodero, Emma (2020). "Radio: the medium that best copes in crises. Listening habits, consumption, and perception of radio listeners during the lockdown by the Covid-19". El profesional de la información, v. 29, n. 3, e290306.

https://doi.org/10.3145/epi.2020.may.06

Rojas-Torrijos, José-Luis; Jimeno-López, Miguel-Ángel (2019). "La presencia de las mujeres deportistas en la prensa regional en España. Un análisis de la fotografía de portada”. Communication papers, v. 8, n. 16, pp. 33-33. https://doi.org/10.33115/udg_bib/cp.v8i16.22357

Sánchez-Aranda, José-Javier (2005). "Análisis de contenido cuantitativo de medios". En: Berganza-Conde, María-Rosa; Ruiz-San-Román, José A. (coords.). Investigar en comunicación. Guía práctica de métodos y técnicas de investigación social en Comunicación. Madrid: McGraw Hill, pp. 207-228. ISBN: 8448198255

Scheufele, Bertram (2004). "Framing-effects approach: A theoretical and methodological critique". The European journal of communication research, v. 24, n. 4, pp. 401-428.

https://doi.org/10.1515/comm.2004.29.4.401

Semetko, Holli A.; Valkenburg, Patti M. (2000). "Framing European politics: A content analysis of press and television news". Journal of communication, v. 50, n. 2, pp. 93-109.

https://doi.org/10.1111/j.1460-2466.2000.tb02843.x

Shaw, Donald L.; Martin, Shannon E. (1992). "The function of mass media agenda setting". Journalism quarterly, v. 69, n. 4, pp. 902-920. https://doi.org/10.1177/107769909206900410

Smith, Katherine C.; Rimal, Rajiv N.; Sandberg, Helena; Storey, John D.; Lagasse, Lisa; Maulsby, Catherine; Rhoades, Elizabeth; Barnett, Daniel J.; Omer, Saad B.; Links, Jonathan M. (2013). "Understanding newsworthiness of an emerging pandemic: International newspaper coverage of the H1N1 outbreak". Influenza and other respiratory viruses, v. 7, n. 5, pp. 847-853.

https://www.ncbi.nlm.nih.gov/pmc/articles/PMC4941752/

https://doi.org/10.1111/irv.12073

Van-Gorp, Baldwin (2007). "The constructionist approach to framing: Bringing culture back in". Journal of communication, v. 57, n. 1, pp. 60-78.

https://doi.org/10.1111/j.1460-2466.2006.00329_3.x

Weaver, David H. (2007). "Thoughts on agenda setting, framing, and priming". Journal of communication, v. 57, n. 1, pp. 142-147

https://doi.org/10.1111/j.1460-2466.2006.00333.x

Wimmer, Roger D.; Dominick, Joseph R. (1996). La investigación científica de los medios de comunicación. Una introducción a sus métodos. Bosch. ISBN: 9788476763599 